\title{
Clinical experience and critical evaluation of the role of sorafenib in renal cell carcinoma
}

This article was published in the following Dove Press journal:

Open Access Journal of Urology

13 May 201 I

Number of times this article has been viewed

\author{
Fable Zustovich' \\ Giuseppe Lombardi' \\ Davide Pastorelli' \\ Patrizia Farina' \\ Massimo Dal Bianco ${ }^{2}$ \\ Luca De Zorzi \\ Maurizia Dalla Palma' \\ Ornella Nicoletto' \\ Vittorina Zagonel' \\ 'Oncologia Medica I, Istituto \\ Oncologico Veneto-IRCCS, Padova, \\ Italy; ${ }^{2}$ UO Urologia, Ospedale \\ Sant'Antonio, ULSS 16, Padova, Italy
}

Correspondence: Fable Zustovich Istituto Oncologico Veneto, IRCCS, Via Gattamelata n. 64, 35 I 28 Padova, Italy

Tel +393479775504

Fax +390498215904

Email fable.zustovich@ioveneto.it

\begin{abstract}
Renal cell carcinoma (RCC) is a common malignancy worldwide with approximately 95,000 new cases per year and ranks as the sixth cause of cancer deaths. Until recently, the slightly active and very toxic cytokines were available for patients with advanced RCC. Advances have been made in understanding the molecular biology of renal cancer. The introduction of targeted agents has led to promising possibilities for treating these highly vascularized tumors. Angiogenesis inhibition is likely to represent the main potential therapeutic target. Sorafenib is an oral multikinase inhibitor with activity against tyrosine kinase receptors that are responsible for blood vessel development and has shown to be active in treating advanced RCC. In this review, we summarize the pharmacology, mode of action, pharmacokinetics, and safety of sorafenib use in therapy for advanced RCC.
\end{abstract}

Keywords: sorafenib, pharmacokinetics, angiogenesis

\section{Introduction to the management issues in the treatment of metastatic advanced renal cell carcinoma: clinical effects of sorafenib}

Renal cell carcinoma (RCC) represents the main form of kidney cancer and accounts for $90 \%-95 \%$ of tumors of the kidney. This pathology arises from cells of the renal tubule and represents approximately $2 \%$ of all adult malignant tumors. ${ }^{1} \mathrm{RCC}$ is the sixth leading cause of cancer death and is responsible for an estimated 95,000 deaths worldwide. ${ }^{2,3}$ Recently, the number of individuals diagnosed with RCC has dramatically increased. ${ }^{4}$ Locally advanced and/or unresectable RCC is defined as advanced RCC, with median survival estimated at 6-12 months and a 2-year survival rate of $10 \%-20 \% .{ }^{5}$ At first diagnosis, approximately $25 \%$ of patients have metastatic disease, and this number rises to $33 \%$ when those patients who develop metastatic spread throughout the course of the disease are also considered. The main histological subtypes of RCC are clear cell, papillary, chromophobic, oncocytic, collecting duct carcinomas, and unclassified. Clear cell carcinoma is the most common form of renal tumor and accounts for $70 \%-80 \%$ of all cases of RCC. ${ }^{6}$

$\mathrm{RCC}$ is resistant to classic systemic therapies and radiation therapy. A large metaanalysis including more than 50 trials revealed an average response rate (RR) of 5.5\% for chemotherapy in RCC patients. ${ }^{7}$ In the last 25 years, the overall prognosis for patients with RCC has not significantly improved. Immunotherapy using cytokine-based regimens was the mainstay of treatment for metastatic disease, although it was effective in only a small minority of patients. ${ }^{9}$ However, the toxicity profile of cytokines limits 
high-dose use to those patients with a good prognosis profile because this setting of patients may tolerate the associated adverse events (AEs) better. ${ }^{9-11}$

\section{Signaling pathways and targeted therapies in RCC}

The most frequent molecular abnormality in clear cell RCC is Von Hippel-Lindau (VHL) inactivation due to loss of the VHL gene, and subsequently upregulation of hypoxiainducible factor 1 alpha (HIF-1 $\alpha$ ) and HIF-2 $\alpha$. Tumor cell proliferation is stimulated by signaling molecules that activate receptor tyrosine kinases (TKs), including vascular endothelial growth factor (VEGF) and platelet-derived growth factor (PDGF). Although PDGFs support vessel stabilization through the recruitment and maturation of pericytes, VEGFs differentially activate Raf kinase ${ }^{12}$ resulting in endothelial cell protection from apoptosis and, in the stimulation of proliferation, providing conditions that are favorable to neovascularization. ${ }^{13}$ Neovascularization is a regulated process in which the proliferation of vascular endothelial cells, lymphangiogenic endothelial cells, and smooth muscle cells that support new blood vessels are controlled by multiple growth factors that bind to TKs. ${ }^{14}$ Therefore, activation of TK signaling pathways is an important mechanism by which most human tumors are stimulated to proliferate and by which tumor-associated neovascularization is initiated and stabilized. Also, mammalian target of rapamycin (mTOR) signaling is a second critical point for pathogenesis of RCC. mTOR controls production of HIF-1 $\alpha$, driving the expression of hypoxic stress response genes that include the same angiogenic growth factors. ${ }^{15}$ All these factors that determine increased cellular proliferation and angiogenesis in RCC have now become rational therapeutic targets.

In the last 5 years, the therapeutic approach to RCC has evolved from cytokines, following the introduction of drugs targeting the VEGF and its receptors (VEGFR 1, 2, 3), the PDGF receptor beta (PDGFR- $\beta$ ), and mTOR pathways. ${ }^{15,16}$ Several antiangiogenic drugs studied for the treatment of patients with RCC have shown to improve progression-free survival (PFS). In second-line treatment of RCC, sorafenib, compared with placebo, was able to double PFS in patients previously treated with cytokines, ${ }^{17}$ and sunitinib, in a firstline study versus interferon (IFN), emerged as a front-line standard of care. ${ }^{18}$ Compared with placebo, pazopanib reduced the risk of tumor progression or death in either cytokine-pretreated patients or untreated patients. ${ }^{19}$ Axitinib and tivozanib are still under development. The mTOR inhibitor temsirolimus has shown good activity in a first-line setting of patients with poor risk features. ${ }^{20}$ Everolimus improves PFS in patients with two or more lines of therapy with tyrosine kinase inhibitors (TKIs). ${ }^{21}$ Finally, the combination of bevacizumab plus IFN is significantly superior to IFN alone. ${ }^{22,23}$ All these new drugs have dramatically changed the scenario of the treatment of RCC in the last 5 years.

Historically, sorafenib is the first target therapy providing activity in RCC with a Phase III trial.

\section{Review of pharmacology, mode of action, and pharmacokinetics of sorafenib}

The bi-aryl-urea sorafenib tosylate is a solid nonchiral molecule and has the chemical name 4-(4-\{3-[4-chloro-3-(trifluoromethyl) phenyl]ureido ; phenoxy)-N2-methylpyridine-2-carboxamide-4methylbenzenesulfonate. During the development of the medicinal product sorafenib and sorafenib tosylate were referred to as BAY 43-9006 and BAY 54-9085, respectively.

Sorafenib tosylate is a substance that is practically insoluble in water, slightly soluble in alcohols, and soluble in dimethyl suphoxide and dimethylformamide. The active substance displays polymorphism and it crystallizes in three different modifications.

Sorafenib discovery is secondary to molecular behavior related to the Raf-1 gene in cell regulation. The first proof of concept that the Raf- 1 gene is a valid anticancer target goes back to 1989 when it was demonstrated that the disruption of the Raf-1 gene inhibits the growth of a large number of human tumors. As a consequence, the screening of drugs with Raf-1 kinase inhibitory activity was initiated. ${ }^{24}$ Early investigations carried out in cell lines have shown that sorafenib directly inhibits downstream Raf kinase isoforms (wild-type Raf-1, B-Raf, and mutant B-Raf V600E). The drug is also able to block the autophosphorylation of several TK receptors such as VEGFR1, 2, and 3, PDGFR- $\beta$, c-Kit, and RET. Therefore,

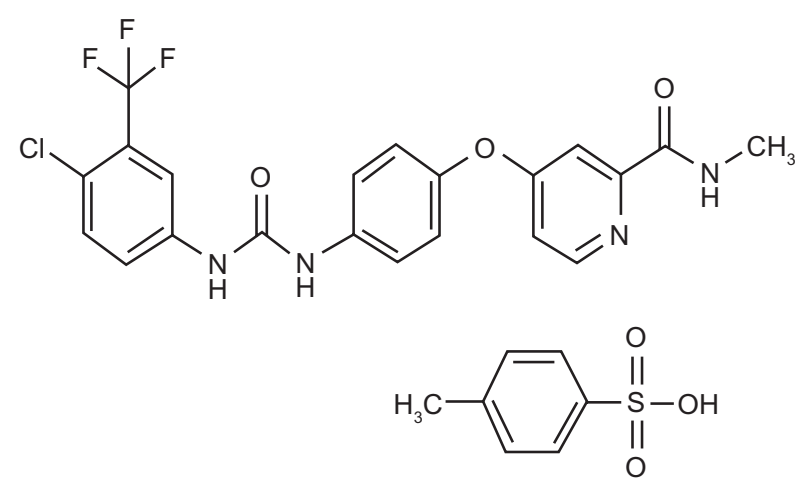

Figure I Sorafenib tosylate chemical structure. 
sorafenib is a dual-action drug capable of inhibiting both tumor cell proliferation and tumor angiogenesis. ${ }^{24}$ It is likely that the mechanism of action of this drug has not yet been completely elucidated because, as has been demonstrated in a wide range of tumor models, it seems to be able to increase the rate of apoptosis. ${ }^{24,25}$ Therefore, on account of its ability to inhibit angiogenesis and the Raf kinase pathway, sorafenib has been identified as a suitable and ideal candidate for studies in RCC (Figure 2).

Sorafenib is a potent inhibitor of C-RAF and wild-type and mutant (V600E) B-Raf with inhibitory concentration (IC50) of $6 \mathrm{nM}, 22 \mathrm{nM}$, and $38 \mathrm{nM}$, respectively. Sorafenib is also a potent inhibitor of several receptor TKs linked to tumor progression, including Flt-3, c-Kit, VEGFR2, VEGFR3, and PDGFR- $\beta$. Sorafenib does not inhibit MEK-1, ERK-1, EGFR, HER2/NEU, c-MET, PKA, PKB, IGFR-1, Cdk-1/ cyclin B, PIM-1, GSK 3-b, CK-2, PKC- $\alpha$, PKC- $\beta$, or PKC- $\gamma$ at concentrations up to $10 \mathrm{nM}^{26}$

The mean terminal half-life determined for sorafenib across studies in humans varied between 25 hours and 48 hours. Sorafenib reaches peak plasma levels 3 hours after oral administration. Sorafenib bioavailability decreases with a high-fat meal, but there is no impact of a moderate-fat meal (approximately $30 \%$ of calories from fat) on sorafenib bioavailability compared with the fasted state. In vitro binding of sorafenib to human plasma proteins is $99.5 \% .^{27}$

Sorafenib is metabolized primarily in the liver and undergoes oxidative metabolism mediated by cytochrome P450 (CYP)3A4, as well as glucuronidation mediated by
UGT1A9. Sorafenib is a moderate inhibitor of CYP2C19, CYP2D6, CYP3A4, CYP2B6, CYP2C8, and CYP2C9, and the evaluation of the in vitro enzyme induction potential of sorafenib showed no activation of CYP2C19 and CYP23A enzyme activity. ${ }^{28}$ Sorafenib accounts for $70 \%-85 \%$ of the circulating analytes in plasma at steady state. Eight metabolites of sorafenib have been identified, of which five have been detected in plasma. The main circulating metabolite of sorafenib in plasma, the pyridine N-oxide M2, shows in vitro potency similar to that of sorafenib. Following oral administration of a $100 \mathrm{mg}$ sorafenib dose in solution, $96 \%$ of a sorafenib dose was recovered within 14 days of administration, with $77 \%$ excreted in the feces and $19 \%$ in the urine as glucuronidated metabolites. Unchanged sorafenib was found in the feces (51\% of the dose) but not in the urine..$^{28}$ No pharmacokinetic data exist for pediatric patients. For adults, no dose adjustments are needed according to age or gender. On the contrary, ethnicity has been shown to influence the pharmacokinetic parameters. A comparison between Japanese patients and Caucasian patients indicates that in the former cohort, sorafenib area under the plasma concentration-time curve (AUC) values are $45 \%$ lower with a significant overlap in the range of exposure observed in the two groups. ${ }^{28,29}$ Pharmacokinetic data resulting from patients with mild (Child-Pugh A, $n=14$ patients) or moderate (Child-Pugh B, $\mathrm{n}=8$ ) hepatic impairment reported that exposure and safety were comparable in these patients. No dose adjustment is necessary when administering sorafenib to patients with Child-Pugh A and B hepatic impairment. ${ }^{30}$
Tumour cell

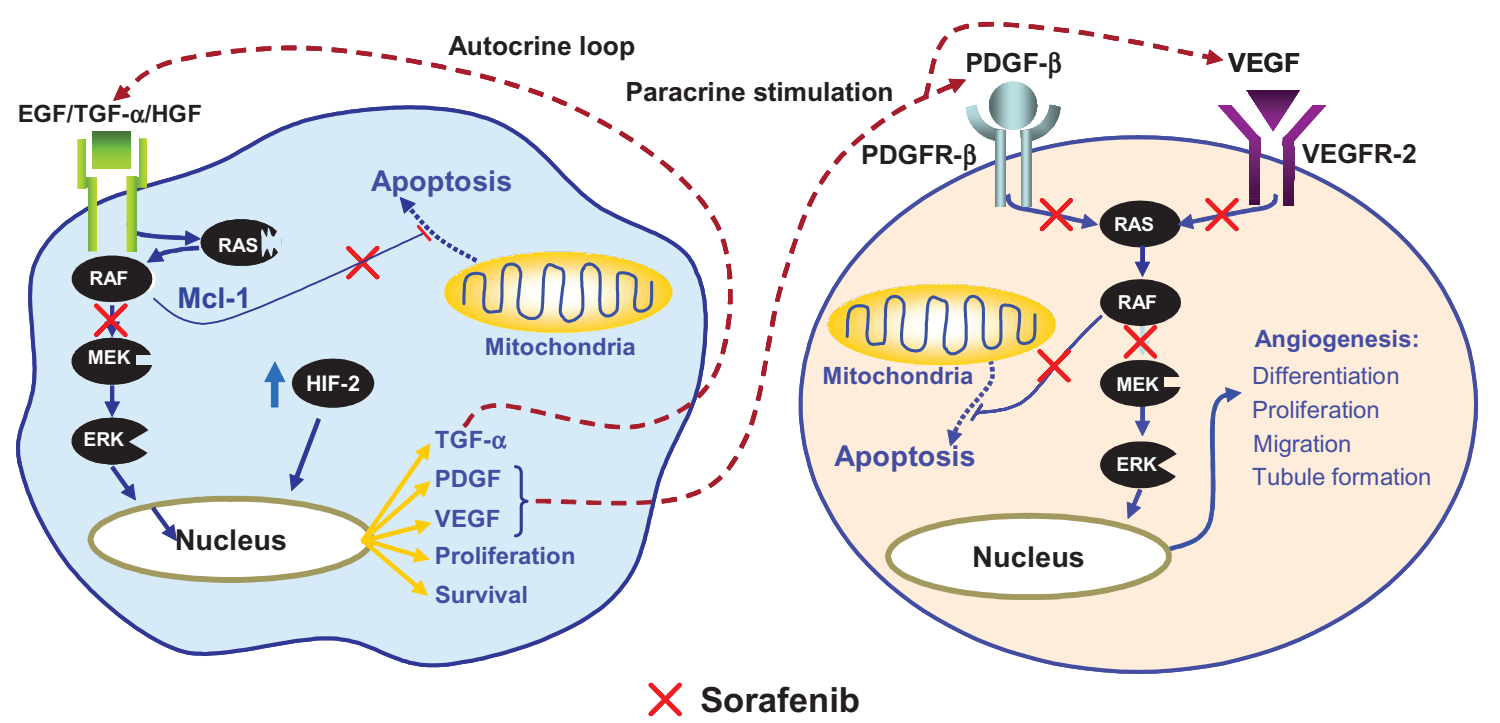

Figure 2 Sorafenib targets both tumor cells and angiogenesis supporting tumor growth. Copyright (c) 20I I, Forum Service. Reproduced with permission from Porta and Bracarda. ${ }^{31}$ 
Sorafenib's pharmacokinetics have not been studied in patients with severe hepatic impairment (Child-Pugh C). In four Phase I clinical trials, sorafenib was evaluated in 71 patients with normal renal function, 24 patients with mild renal impairment (creatinine clearance $>50-80 \mathrm{~mL} / \mathrm{min}$ ), and four patients with moderate renal impairment (creatinine clearance $30-50 \mathrm{~mL} / \mathrm{min}$ ). No relationship was observed between renal function and steady state sorafenib AUC at doses of $400 \mathrm{mg}$ twice daily. The drug's pharmacokinetics has not been studied in patients with severe renal impairment (creatinine clearance $<30 \mathrm{~mL} / \mathrm{min}$ ) or in patients undergoing dialysis. ${ }^{32-34}$

Steady state dosing of ketoconazole (400 mg), a potent inhibitor of CYP3A4, did not alter the mean AUC of an oral dose of sorafenib. Administration of sorafenib tablets did not alter the exposure of concomitantly given midazolam (CYP3A4 substrate), dextromethorphan (CYP2D6 substrate), or omeprazole (CYP2C19 substrate). The possible effects of sorafenib on the CYP2C9 substrate warfarin were assessed indirectly by measuring the effects on prothrombin time and international normalized ratio (PT-INR). Mean changes from baseline in PT-INR were no higher in patients administered sorafenib tablets compared with patients given a placebo. Although not studied clinically, inducers of CYP3A4 activity are expected to increase metabolism of sorafenib and thus decrease sorafenib concentrations. ${ }^{28}$ Sorafenib tablets have been given with the antineoplastic agents gemcitabine, oxaliplatin, doxorubicin, and irinotecan. Concomitant treatment with sorafenib resulted in a $21 \%$ increase in the AUC of doxorubicin. When given with irinotecan, whose active metabolite SN-38 is further metabolized by the UGT1A1 pathway, sorafenib produced a $67 \%-120 \%$ increase in the AUC of SN-38 and a 26\%-42\% increase in the AUC of irinotecan. ${ }^{27}$ In vitro, sorafenib inhibited CYP2B6, CYP2C8, CYP2C9, glucuronidation by UGT1A1 and UGT1A9, and P-glycoprotein. Systemic exposure to substrates of CYP2B6 (bupropion, cyclophosphamide, efavirenz, ifosfamide, methadone) and CYP2C8 (paclitaxel, amodiaquine, repaglinide) or CYP2C9 substrates (eg, warfarin) might be expected to increase when coadministered with sorafenib. Although coadministration of sorafenib and warfarin did not alter the INR, patients receiving warfarin or phenprocoumon should have their INR regularly monitored. ${ }^{27}$ Similarly, systemic exposure to substrates of UGT1A1 and UGT1A9 may increase when coadministered with sorafenib. At present, the clinical relevance of the in vitro inhibition of glucuronidation via UGT1A1 and UGT1A9 is unknown. CYP1A2 and CYP3A4 activities were not altered after treatment of cultured human hepatocytes with sorafenib, showing that sorafenib is unlikely to be an inducer of CYP1A2 and CYP3A4 in vivo. However, AUC was reduced by an average of $37 \%$ with concomitant administration of the CYP3A4 inducer rifampicin. Sorafenib concentrations may also be decreased by other CYP3A4 inducers, such as hypericum (St John's wort), phenytoin, carbamazepine, and phenobarbital. ${ }^{27}$

\section{Clinical efficacy studies}

Following are details of the pivotal studies for sorafenib registration in $\mathrm{RCC}$.

\section{Phase I}

Four Phase I studies in 163 patients identified $400 \mathrm{mg}$ twicedaily continuous dosing as the recommended Phase II dose of sorafenib. ${ }^{32,35,36}$ A fifth Phase I trial was conducted to evaluate the pharmacokinetics of sorafenib in patients with hepatic or renal dysfunction. ${ }^{32,35,36}$ The most common dose-limiting toxicities were grade 3 diarrhea, fatigue, and skin toxicity. All toxicities were reversible on cessation of sorafenib. These findings provided the basis for Phase II studies of sorafenib in RCC.

\section{Phase II}

The first multicenter, placebo-controlled, randomized, Phase II discontinuation study evaluated sorafenib in patients with advanced refractory cancer. ${ }^{37}$ Originally, the study focused mainly on patients with colorectal carcinoma, but as tumor responses were observed in patients with RCC and those without treatment options, this group of patients was expanded and 202 patients with RCC were included.

The primary efficacy endpoint was PFS rate at 12 weeks after randomization. Secondary endpoints included the level of responses evaluated with World Health Organization (WHO) criteria. Dose modification due to toxicity allowed $200 \mathrm{mg}$ bid and $200 \mathrm{mg}$ qd. All patients were treated with sorafenib 400 bid for 12 weeks (Figure 3).

Patients with stable disease at 12 weeks after initial therapy with sorafenib were randomized to receive placebo or sorafenib while responders continued on active therapy. Patients with progressive disease went off study. A total of 187 patients with RCC completed 12 weeks of sorafenib therapy, and 65 underwent randomized withdrawal while 79 continued on open-label sorafenib. PFS after randomization in the placebo group was 41 days versus 163 days in the sorafenib continuation group $(P=0.0001)$. At 12 weeks postrandomization, $16 / 32$ of the patients randomized to 


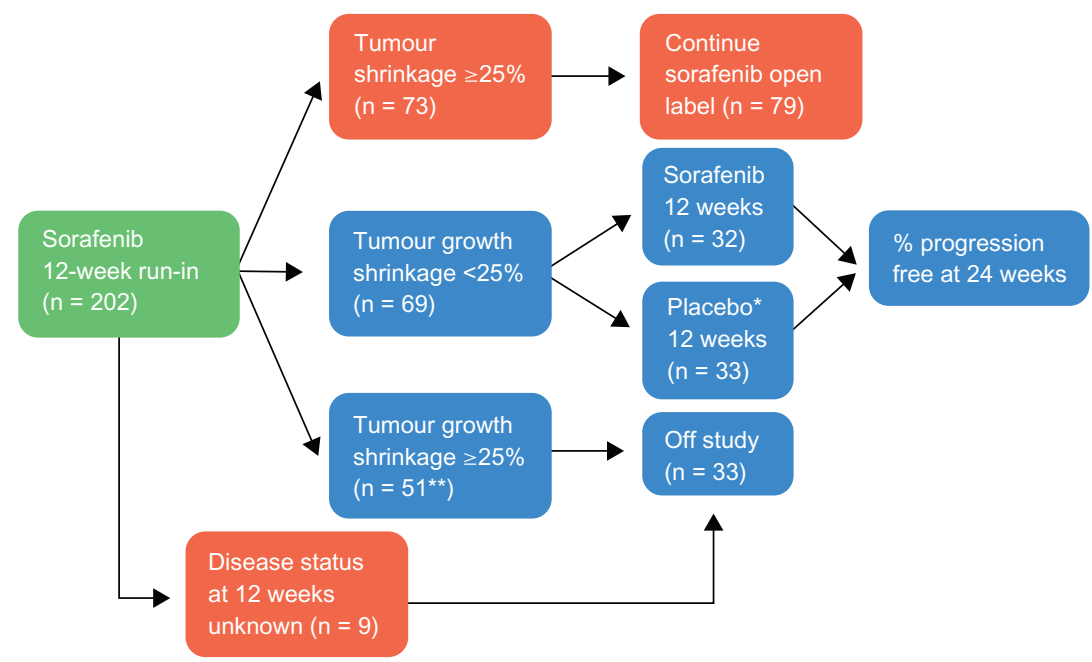

Figure 3 Phase II design.

Notes: *Placebo patients who progressed could cross over to sorafenib; **Including 36 patients without bidimentional tumor measurements, but with radiological evidence of progression.

Copyright (c) 20II, Forum Service. Reproduced with permission from Porta and Bracarda. ${ }^{31}$

sorafenib were progression free versus $6 / 33$ in the placebo group $(P=0.008)$. An independent review of tumor response was undertaken in 152 patients, and the partial RR was $4 \%$ (8/202) (Figure 4).

At the 2006 American Society of Clinical Oncology annual meeting, Escudier et $\mathrm{al}^{40}$ presented a subgroup analysis of 32 treatment-naïve patients, resulting from a Phase II, randomized, discontinuation trial. Best response (investigator assessed according to WHO criteria) was partial response in six patients (18.8\%), minor response in eight patients $(25.0 \%)$, and stable disease in 10 patients (31.3\%), giving a disease control rate (DCR), which is the sum of complete response plus partial response plus stable disease for $\geq 8$ weeks, of $75 \%$. Median PFS for all 32 patients was 40 weeks.

A second open-label Phase II study of sorafenib $400 \mathrm{mg}$ bid was conducted in Japanese patients with RCC who failed at least one cytokine-containing therapy. ${ }^{33}$ Among 129 patients, confirmed partial response was observed in 16 patients $(12.4 \%)$, stable disease was observed in

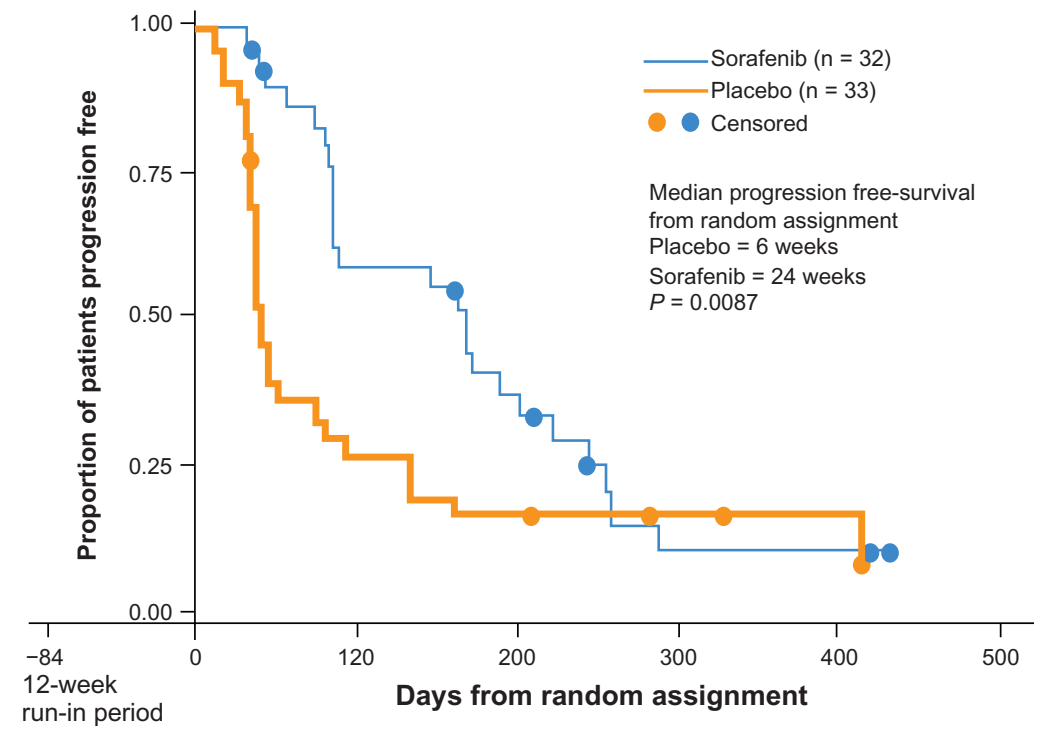

Figure 4 Phase II Kaplan-Meier PFS curve.

Copyright $@ 201$ I, Forum Service. Reproduced with permission from Porta and Bracarda. ${ }^{31}$ 
93 patients $(72.1 \%)$, and 103 patients $(80.5 \%)$ had tumor shrinkage. Median PFS was 224 days.

A third randomized, Phase II study investigated the efficacy, safety, and quality of life (QoL) with first-line sorafenib versus IFN (9 MIU tiw). The study involved 189 patients with advanced clear cell RCC who had received no prior systemic therapy. ${ }^{39}$ Patients who progressed while receiving sorafenib $400 \mathrm{mg}$ bid could have their dose increased to $600 \mathrm{mg}$ bid, whereas patients who progressed while receiving IFN could cross over to sorafenib $400 \mathrm{mg}$ bid. Although no statistical difference in the primary endpoint was shown, sorafenib was associated with a higher tumor regression rate than IFN. Sorafenib-treated patients reported significantly fewer kidney cancer-related symptoms. There was a trend toward better overall QoL and greater global treatment satisfaction for sorafenib-treated patients than for patients who received IFN. Sorafenib-treated patients also had a significantly longer time to health status deterioration than did IFN-treated patients. ${ }^{39}$

\section{Phase III}

The Treatment Approaches in Renal Cancer Global Evaluation Trial (TARGET) was the largest multicenter, randomized, Phase III trial conducted to date in patients with advanced RCC. ${ }^{17}$

The study enrolled 903 patients with advanced RCC that had progressed within the previous 8 months after one systemic therapy. The study involved 117 centers in 19 countries. Most patients enrolled in TARGET had received cytokinebased therapy (82\%); however, patients who had received other systemic therapies, such as hormonal therapies and/ or antineoplastic agents, were not excluded from enrolment in TARGET. Patients were administered either sorafenib $400 \mathrm{mg}$ plus best supportive care (BSC) or placebo plus BSC twice daily on a continuous basis, without food or with a moderate-fat meal. The primary objective was to evaluate the efficacy (overall survival [OS]) of sorafenib compared with placebo. The secondary objectives were to evaluate the efficacy by PFS, RR evaluated with Response Evaluation Criteria in Solid Tumors (RECIST) criteria (RR is the sum of complete response plus partial response), changes in healthrelated QoL, and symptom response. OS was determined based on findings on computed tomography or magnetic resonance imaging, clinical progression, or death, with the use of RECIST. A single planned interim analysis showed that the median PFS was 5.5 months in the sorafenib group and 2.8 months in the placebo group (167 vs 84 days).

As a result, it was agreed that it would not be ethical to continue the study with a placebo control arm. Thus, the study was modified and a crossover was permitted from placebo to sorafenib. It was also determined at this time that allowing patients to cross over might compromise the endpoint of OS, and the protocol were amended to allow a planned post hoc analysis (preplanned analysis) of OS at the start of the treatment crossover, thereby eliminating the confounding effect of the patients who crossed over from placebo (Table 1).

The final planned OS analysis showed an improvement of $13.5 \%$ for sorafenib versus placebo (median 17.8 vs 15.2 months; hazard ratio [HR] 0.88; 95\% confidence interval [CI] 0.74-1.04, $P=0.146$, O'Brien-Fleming threshold for statistical significance $\alpha=0.037$ ).

The preplanned secondary analysis censoring placebo patients at crossover showed a significant OS benefit for sorafenib versus placebo (median 17.8 vs 14.3 months, HR 0.78, 95\% CI 0.62-0.97, $P=0.0287 ; \alpha=0.037){ }^{40}$

Partial response was reported in $10 \%$ of patients receiving sorafenib versus $2 \%$ receiving placebo. Traditionally, parameters used to measure RR were developed to evaluate antitumor effects of systemic cytotoxic therapies. ${ }^{17}$ Moreover, tumor shrinkage was observed in most patients treated with sorafenib, and significantly more patients in the sorafenib group than in the placebo group had partial response or stable disease $(P<0.001)$ (Table 1$)$.

One of the most important findings from TARGET was that the use of the traditional dimensional criteria to assess tumor regression may not be the best way to assess possible clinical benefits of newer, targeted therapies. ${ }^{41,42}$ In fact, sorafenib, with other new target therapies, causes disease

Table I TARGET study: overall survival analysis

\begin{tabular}{|c|c|c|c|c|c|}
\hline & \multicolumn{5}{|c|}{ OS in TARGET study (months) } \\
\hline & $\begin{array}{l}\mathbf{N} \\
\text { events }\end{array}$ & Sorafenib & Placebo & HR & $p$ \\
\hline $\begin{array}{l}\text { First Interim } \\
\text { analysis before } \\
\text { crossover } \\
\text { (May 2005) }\end{array}$ & 220 & - & 14,7 & 0,71 & 0.015 \\
\hline $\begin{array}{l}\text { Second interim } \\
\text { analysis } 6 \text { months } \\
\text { after crossover } \\
\text { (November 2005) }\end{array}$ & 367 & 19,3 & 15,9 & 0,77 & 0.015 \\
\hline $\begin{array}{l}\text { Final OS analysis } \\
16 \text { months after } \\
\text { crossover } \\
\text { (September 2006) }\end{array}$ & 561 & 17,8 & 15,2 & 0,88 & 0,146 \\
\hline $\begin{array}{l}\text { Preplanned } \\
\text { analysis }\end{array}$ & 424 & 17,8 & 14,3 & 0,78 & $0,029 *$ \\
\hline
\end{tabular}


stabilization rather than substantial tumor regression, requiring new surrogate markers to evaluate drug benefit. After TARGET, a new consciousness for alternative trial endpoints (PFS or OS) gets stronger.

\section{Expanded-access programs}

The primary objective of the Advanced Renal Cell Carcinoma Sorafenib (ARCCS) North American (NAARCCS) and European (EU-ARCCS) studies was to make sorafenib available to patients with advanced RCC who did not have access to, or were not eligible for, other clinical trials with sorafenib. The efficacy and safety of sorafenib demonstrated in the setting of TARGET were confirmed in expanded-access studies conducted in Europe and North America.

\section{North American ARCCS}

NA-ARCCS, an open-label, nonrandomized, expandedaccess program, included 2502 advanced RCC patients from the US and Canada $(n=1247$ first line, $n=1255$ second line). Responses were assessed by the investigator, and a large percentage of the data were incomplete or missing. Additionally, the study had a short follow-up due to the approval of sorafenib and high rates of censoring for the PFS endpoint (Figure 5).

Response was evaluated in 1871 patients $(n=935$ first line, $\mathrm{n}=936$ second line), and the DCR was $85 \%$ for firstline patients and $84 \%$ for subsequent lines of therapy. The median of PFS of the whole population was 24 weeks without evident differences between fist-line and precedent-treated patient subgroups.

A subset of patients who were evaluated included 136 patients with nonclear cell histology (118 papillary,

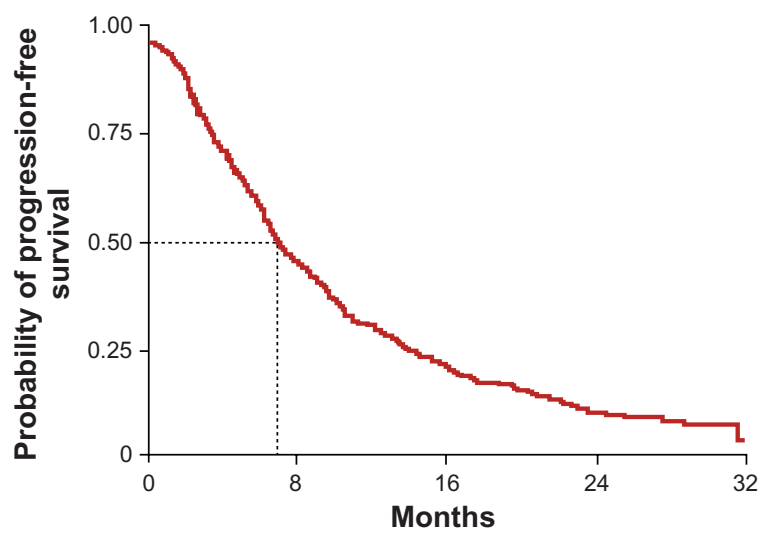

Figure 5 A-ARCCS Kaplan-Meier PFS curve.

Copyright (C) 20II, Forum Service. Reproduced with permission from Porta and Bracarda. ${ }^{31}$
18 chromophobe), 197 with prior bevacizumab use, and 50 with brain metastases. RRs for different subsets of patients were similar. Patients with papillary tumors received a clinical benefit of $84 \%$, and patients with chromophobe tumors obtained a clinical benefit of $90 \%{ }^{43}$

\section{European ARCCS}

EU-ARCCS was an open-label, expanded-access study that evaluated the safety and efficacy of sorafenib in 1155 patients with advanced RCC who had failed one or more systemic therapies or who were unsuitable for cytokine therapy. Patients with asymptomatic, controlled brain metastases were permitted to participate. The study subjects received sorafenib $400 \mathrm{mg}$ bid until progression, intolerable toxicity, or consent withdrawal. The endpoints of the study were PFS, RR, and safety. ${ }^{44}$

A total of $28 \%$ (318 of 1155 ) of patients included in this trial were considered unsuitable for cytokine treatment and were therefore treatment naïve. The other patients had failed one or more prior therapies including IFN $\alpha(n=681,59 \%)$, interleukin-2 $(n=369,32 \%)$, bevacizumab $(n=42,4 \%)$, and sunitinib $(n=69,6 \%)$. Twenty-eight patients with brain metastases received sorafenib (Figure 6).

The DCR, according to investigator-assessed response data for 1031 EU-ARCCS patients, was $72.8 \%$, with a median PFS of 6.8 months (95\% CI $6.2-7.5$ months; $45 \%$ of patients censored as they were on treatment at data cut-off). RR was evaluable in 1031 patients. The level of partial response was $1.8 \%$ and stable disease was $71 \%$ with a clinical benefit of $72.8 \%$

Sorafenib was well tolerated among patients enrolled in EU-ARCCS, with similar frequencies of AEs to those reported for the agent in the second-line setting.

Exploratory analyses suggested that sorafenib was efficacious in a number of subpopulations, including patients deemed inappropriate for cytokine therapy, patients older than 65 years of age, patients with hereditary RCC, and patients with brain or bone metastases or papillary or other histologic features. Sorafenib $400 \mathrm{mg}$ bid appeared to provide clinical benefit for patients who had failed at least one line of cytokine therapy as well as for patients who had failed prior antiangiogenic therapy. ${ }^{44,60}$

\section{Prospective comparative studies with targeted therapies}

No prospective studies have directly compared the effectiveness of sorafenib with other targeted therapies in the treatment of advanced RCC. The currently available studies do not measure the same outcomes, making it difficult to compare these medications. 
A

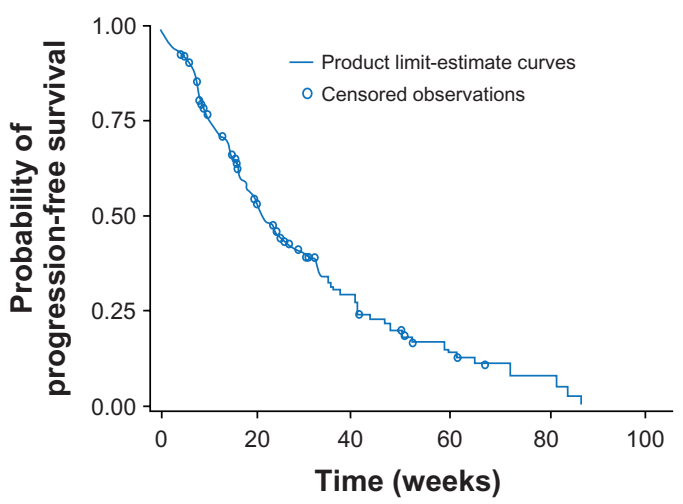

B

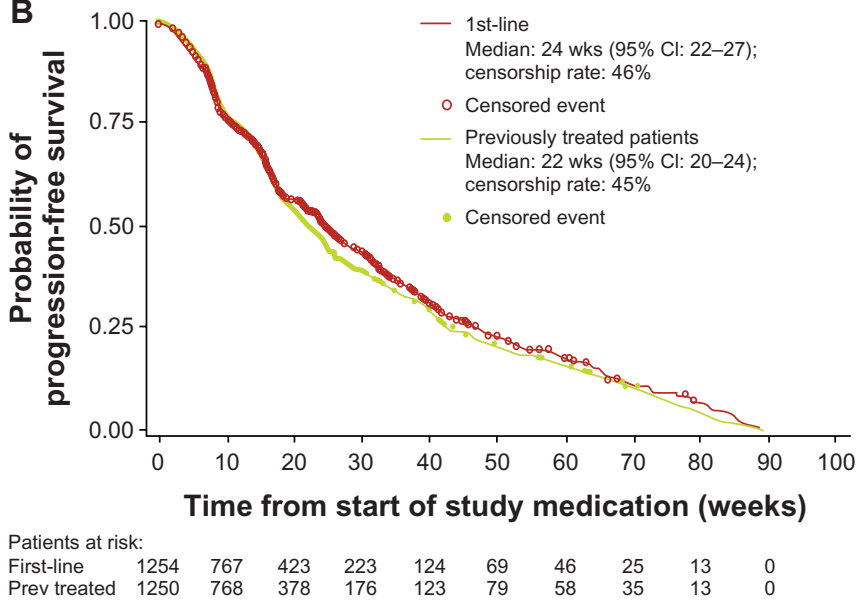

Figure 6 EU-ARCCS: PFS in the study (A) and in first line subgroup of patients (B). Copyright (C) 2011, Forum Service. Reproduced with permission from Porta and Bracarda. ${ }^{31}$

\section{Clinical safety: detailed safety and tolerability issues}

Data referring to clinical trial RCC patients highlight the good toxicity profile of sorafenib. The drug appears to be well tolerated, and drug-related AEs are well known. In TARGET, the rates of early therapy discontinuation in the active treatment and placebo arms were comparable ( $10 \%$ vs $8 \%$, respectively). ${ }^{17}$ Overall, expanded-access studies of sorafenib in advanced RCC in North America (NA-ARCCS) and Europe (EU-ARCCS) show the same safety prolife as in the clinical setting. Toxicity appears to be similar independently from rigidly selected patients from clinical trials or patients enrolled in common clinical practice (Table 2) ${ }^{43}$

Most AEs seen with sorafenib are slight or moderate (grade 1-2). Incidence of severe AEs is modest. ${ }^{17,43}$ The most common AEs reported during sorafenib therapy are diarrhea, skin rash, astenia, hand-foot skin reaction (HFSR), hypertension, mucositis, alopecia, and nausea. Reasons for discontinuation are skin/gastroenterological toxicities and primarily diarrhea. ${ }^{17} \mathrm{AE}$ management may require temporary drug discontinuation until the end of the disorder and/or dose reduction.

In cases of severe toxicity, drug dose could be reduced to $400 \mathrm{mg} /$ day, generally with clinically good results. In cases of rare AEs, such as bowel perforation or bleeding requiring medical intervention, sorafenib discontinuation is mandatory. Similarly, temporary interruption of sorafenib therapy is recommended in patients undergoing major surgical procedures. The decision to resume sorafenib therapy following a major surgical intervention should be based on clinical judgment of adequate wound healing. 45,63

Clinical trial patients in therapy with sorafenib for a long duration did not seem to experience new toxicity or an increase in overall incidence of treatment-related AEs. No increase in grade 3-4AEs or cardiotoxicity were observed in this long-term therapy population. ${ }^{46}$

\section{Dermatological toxicities}

HFSR and rash represent the most common adverse drug reactions related to sorafenib therapy. Alopecia and pruritus are also commonly occurring AEs. Rash and HFSR are usually grade 1 and 2 . Grade 3-4 adverse drug reactions are reported infrequently for pruritus $(<1 \%)$, alopecia $(<1 \%)$, rash/desquamation $(1 \%-5 \%)$, and HFSR $(6 \%-12 \%) .{ }^{17,43,44}$

\section{Hypertension}

An increased incidence of hypertension was observed in sorafenib-treated patients. In TARGET and the NA-ARCCS and EU-ARCCS expanded-access studies, hypertension (all grades) was reported in $14 \%-17 \%$ of patients, with $4 \%-5 \%$ of cases of grade 3 or 4 severity. ${ }^{17,43,44}$ Hypertension was

Table 2 Grade 3 and 4 adverse events in ARCCS, EU-ARCCS, TARGET trial

\begin{tabular}{|c|c|c|c|}
\hline & $\begin{array}{l}\text { ARCCS }^{43} \\
(n=2337) \\
\text { Grade } \geq 3\end{array}$ & $\begin{array}{l}\text { EU-ARCCS } \\
(n=I \mid 45) \\
\text { Grade } \geq 3\end{array}$ & $\begin{array}{l}\text { Ph III TARGET }{ }^{17} \\
\text { only sorafenib arm } \\
(\mathrm{n}=45 \mathrm{I}) \\
\text { Grade } \geq 3\end{array}$ \\
\hline Any AE & 924 (40\%) & $519(45 \%)$ & $38 \%$ \\
\hline $\begin{array}{l}\text { Hand foot } \\
\text { skin reaction }\end{array}$ & I 78 (8\%) & 149 (I3\%) & $6 \%$ \\
\hline Rash & 97 (5\%) & $60(5 \%)$ & $<1 \%$ \\
\hline Diarrhea & $56(2 \%)$ & 84 (7.3\%) & $2 \%$ \\
\hline Fatigue & 110 (4\%) & 81 (7.l\%) & $5 \%$ \\
\hline Alopecia & $2(<1 \%)$ & $0(0 \%)$ & $<1 \%$ \\
\hline Hypertension & I0I (4\%) & $70(6.1 \%)$ & $3 \%$ \\
\hline Nausea & $39(2 \%)$ & 14 (1.2\%) & $<1 \%$ \\
\hline Bleeding & $32(1 \%)$ & $2(<1 \%)$ & $2 \%$ \\
\hline Dyspnea & $64(2 \%)$ & - & $3 \%$ \\
\hline
\end{tabular}


usually mild to moderate, occurred early in the course of treatment, and was amenable to management with standard antihypertensive therapy.

Blood pressure should be monitored regularly and treated if required, in accordance with standard medical practice. In cases of severe or persistent hypertension or hypertensive crisis, permanent discontinuation of sorafenib should be considered. ${ }^{45,63}$

\section{Cardiac toxicities}

In TARGET, the incidence of treatment-emergent cardiac ischemia/infarction events was higher in the sorafenib group $(2.9 \%)$ than in the placebo group $(0.4 \%)$. Patients with unstable coronary artery disease or recent myocardial infarction were excluded from this study. ${ }^{45,63}$ Temporary or permanent discontinuation of sorafenib should be considered in patients who develop cardiac ischemia and/or infarction. ${ }^{45,63}$ Review of 2276 patients enrolled in trials found a rate of $1.9 \%$ treatment-emergent congestive heart failure. In a study of 53 patients, the mean QTc interval and the mean left ventricular ejection fraction changed minimally after sorafenib treatment compared with baseline, although there were isolated reports of patients with a more than $10 \%$ decrease in left ventricular ejection fraction..$^{45,47,63}$

\section{Hemorrhage}

The incidence of severe bleeding events is uncommon. If any bleeding event necessitates medical intervention, it is recommended that permanent discontinuation of sorafenib should be considered. ${ }^{45,63}$ Hematologic AEs are uncommon with sorafenib. In TARGET, the 3\% rate of grade 3-4 anemia was no different from placebo, and there were no cases of febrile neutropenia or grade 4 thrombocytopenia. ${ }^{17}$ Bleeding (any grade) was more frequent than with placebo, but incidences of serious hemorrhage were not frequent.

\section{Fatigue}

In sorafenib clinical studies, fatigue is a commonly reported AE. In TARGET, the incidence of all-grade fatigue was noted in $37 \%$ of sorafenib- and in $28 \%$ of placebo-treated patients.

\section{Gastrointestinal toxicities}

Diarrhea is the most common intestinal AE of sorafenib. In TARGET, the incidences of nausea, vomiting, and constipation were comparable in sorafenib-treated patients compared with patients taking a placebo. Gastrointestinal perforation is an uncommon event and has been reported in less than $1 \%$ of patients taking sorafenib. Occasionally, it is not associated with apparent intra-abdominal tumor. Sorafenib should be discontinued in cases of gastrointestinal perforation. $^{45,63}$

\section{Renal impairment}

No dose adjustment is required in patients with mild, moderate, or severe renal impairment. One study reported that in patients with RCC, although efficacy was maintained, dose interruption or reduction were required with increasing frequency in patients with an estimated creatinine clearance equal to, or lower than, $60 \mathrm{~mL} / \mathrm{min}$ compared with those with an estimated creatinine clearance higher than $60 \mathrm{~mL} / \mathrm{min}$. Sorafenib experience in patients on hemodialysis is limited and suggests that a reduced starting dose may be required. ${ }^{8,34}$

\section{Hepatic impairment}

No dose adjustment is required in patients with ChildPugh A and B hepatic impairment. Sorafenib has not been studied in patients with Child-Pugh $\mathrm{C}$ hepatic impairment. The optimal dose of sorafenib in nonhepatocellular patients with hepatic impairment is not established, although preliminary data suggest that dose reduction may be necessary. ${ }^{48}$

\section{Other comorbidities}

Many patients with RCC have significant cardiovascular disease, diabetes, and renal or hepatic dysfunction. Agents given for RCC may exacerbate symptoms caused by comorbidities, such as fatigue, and drug interactions with ongoing therapies can cause additional toxicities. Clinically significant abnormalities of thyroid function are uncommon in patients treated with sorafenib, and there is no requirement for monitoring of thyroid function. A pilot study investigating the feasibility of using sorafenib prior to nephrectomy has found no evidence that the agent interferes with surgical technique or increases risk of complications, including bleeding. ${ }^{49}$ No adverse effect on wound healing was seen.

\section{Histology}

In the randomized, placebo-controlled, Phase III trial of sorafenib, TARGET, $100 \%$ of patients harbored clear cell histology. However, the expanded-access cohorts and retrospective trial provide evidence that the efficacy of sorafenib extends to nonclear cell tumors. In the European study, disease control was reported in $66 \%$ of the 104 papillary tumors, $67 \%$ of the 46 sarcomatoid tumors, and $61 \%$ of the 103 with other nonclear cell histologies. ${ }^{43}$ The ARCCS expanded-access program included 118 individuals with papillary and 18 with chromophobe RCC. ${ }^{43}$ Additionally, a retrospective analysis 
reported disease stabilization in 53 patients with either papillary or chromophobe RCC who had been treated with either sorafenib or sunitinib. ${ }^{50}$ Moreover, evidence of clinical benefit with sorafenib has been reported in a small Cleveland Clinic series of patients with sarcomatoid RCC. ${ }^{51}$

\section{Age}

According to the National Cancer Institute, ${ }^{33}$ around 50\% of patients presenting with RCC are aged 65 years or over, and a quarter are aged 75 years and older. ${ }^{52}$ In this setting of patients, comorbidities are more frequent, tolerability is perceived as a greater issue, and outcomes are thought to be worse. ${ }^{53,54}$ AEs such as diarrhea or stomatitis are of concern even when they are low grade. ${ }^{53}$ A retrospective subgroup analysis of the data from TARGET examined the safety and efficacy in older (age $\geq 70$ years, $n=115$ ) and younger (age $<70$ years, $\mathrm{n}=787$ ) patients. ${ }^{55}$ Median PFS and clinical benefit were similar in sorafenib-treated younger patients and older patients. AEs were predictable and manageable regardless of age. In the EU-ARCCS population, PFS and safety were similar to those in the overall TARGET population 113. ${ }^{56,57}$ A subgroup analysis was performed to compare the efficacy and safety of sorafenib in advanced RCC patients with $(n=490)$ or without $(n=658)$ cardiovascular diseases (coronary heart disease, stroke, hypertension, and congestive heart failure). PFS (6.8 months vs 6.9 months, respectively), clinical benefit rates $(76.8 \%$ vs $77.3 \%)$, and safety were similar in the two groups. However, following treatment with sorafenib, the hypertension rate was higher in patients with cardiovascular diseases than in those without ( $8 \%$ vs $2 \%$ ).

\section{Performance status}

Randomized controlled trial data show strong evidence that sorafenib benefits patients with Eastern Cooperative Oncology Group performance status (PS) $0-1 .{ }^{17}$ Expanded-access data suggest that this benefit extends to patients with PS 2 .

\section{Patient-focused perspectives such as quality of life and patient satisfaction/acceptability}

An analysis to evaluate the impact of sorafenib treatment versus placebo on RCC symptoms and QoL was performed during TARGET. ${ }^{58}$ Symptoms were measured by the Functional Assessment of Cancer Therapy (FACT) Kidney Cancer Symptom Index (FKSI) and QoL by the FACT-General (FACT-G). At baseline and over time, there were no differences in mean scores for either FACT-G or FKSI between sorafenib and placebo groups. ${ }^{58}$ Health status deterioration was significantly slower in sorafenib-treated subjects than in those given placebo. Sorafenib shows clinical benefit without adversely affecting overall QoL, with a positive impact on some individual symptoms, such as fatigue, lack of energy, pain, weight loss, fevers, attitude to work, appetite, and enjoyment of life. ${ }^{58}$

These findings are consistent with other clinical results from this trial of advanced RCC subjects treated with sorafenib, which included significantly greater PFS and low risk for treatment-limiting toxicities. ${ }^{43,59}$

To date, some recommendations have been made to improve QoL for patients in the course of sorafenib therapy. These recommendations allow the correct management of sorafenib-related AEs. Unfortunately, no standard guidelines exist for the prevention and management of these AEs.

A well-known sorafenib AE that could deteriorate QoL of patients is HFSR ${ }^{60}$ Although not life threatening, HFSR can severely impact the physical, psychological, and social wellbeing of patients receiving these therapies and can lead to dose reductions and discontinuations that may potentially negate the life-prolonging effects of therapy. ${ }^{61,62}$

No prospective, randomized trials have been conducted to determine the best management of HFSR. Expert recommendations for the management of dermatologic toxicities include preventive measures (eg, having pedicures; wearing thick cotton gloves and/or socks; and avoiding hot water, constrictive footwear, and excessive friction) and topical therapies (eg, moisturizing creams, keratinolytics, topical steroids, or topical analgesics may be considered) for symptomatic relief in grade 1 and 2 HFSR. ${ }^{62}$ Temporary treatment interruption and/or sorafenib dose modification, or in severe or persistent cases permanent discontinuation of sorafenib, may be required to manage HFSR. ${ }^{45,63}$

\section{Conclusion and place in therapy}

At present, randomized controlled trials have proved that five targeted agents are effective in prolong PFS for RCC patients. However, it is not likely that any one therapy will benefit all patients. Treatment should be tailored to meet individual circumstances and needs, and achieving this is a considerable clinical challenge.

Data from expanded-access datasets and clinical experience and retrospective and prospective studies suggest that sorafenib is well suited to many patient subtypes seen in routine practice, including those not represented in pivotal studies. Benefits have been seen independently of age, Memorial Sloan-Kettering Cancer Center risk category, prior 
exposure to cytokines, and presence or absence of lung or liver metastases. ${ }^{17}$

Sorafenib has proven efficacy irrespective of tumor burden and site of metastasis. ${ }^{17}$ The drug remains well tolerated in patients with common comorbidities, including renal and liver dysfunction, and rates of cardiovascular AEs and thyroid dysfunction are consistently low in sorafenib studies. ${ }^{64}$

The European Medicines Agency authorized sorafenib for second-line therapy after cytokine failure or first-line therapy in patients for whom cytokines are unsuitable. ${ }^{63}$ However, because a large number of patients are potentially intolerant or ineligible to immunotherapy, ${ }^{65}$ first-line therapy with sorafenib appears to be a feasible option for selected patient populations. ${ }^{66}$ Moreover, expert opinions suggest using sorafenib in a setting of first-line patients who are potentially unsuitable with classic first lines of target therapy. ${ }^{67}$ Sorafenib use should be considered in a first-line setting of elderly patients with comorbidities, in patients with hypertension that is difficult to manage even with antihypertensive agents, and in patients with renal failure. ${ }^{8,67}$

Sorafenib appears to be the first-line drug of choice for selected patients. Efficacy data on single-agent sorafenib in the first-line treatment of RCC are available from a prospective, randomized, Phase II trial ${ }^{68}$ from data of the North American and European expanded-access programs..$^{43,44}$

In addition, results of Phase II studies with the combination of sorafenib and IFN $\alpha$ in the first-line treatment of RCC have also been reported. ${ }^{69,70}$ Moreover, expert opinions suggest sorafenib use in selected patients, such as elderly RCC patients with comorbidities and first-line patients who prefer a continuous dosing schedule to intermittent dosing with other agents, as they may perceive sorafenib to be easier to manage and offer more control of their care (hypertension). Indeed, toxicity-averse first-line patients may prefer sorafenib due to its tolerability profile and easily adjustable dosing. No evidence on cross-reaction between sorafenib and other VEGF/VEGFR inhibitors seems to exist.

Data available from retrospective and prospective studies and expanded-access programs suggest no cross-resistance between targeted agents. ${ }^{43,71-76}$ In two studies, ${ }^{75,76}$ the authors reported a trend toward longer duration of response in patients receiving sorafenib followed by sunitinib compared with patients receiving sunitinib followed by sorafenib, although the data are limited by the nature of these studies. Taken together, these findings support the use of first-line sorafenib as recommended by the National Comprehensive
Cancer Network and European Organisation for Research and Treatment of Cancer guidelines. ${ }^{54,77}$

At present, we have two options for second-line therapy in RCC: the first is to use everolimus after a first TKI, and the second is to switch the patient to a second TKI, preferring everolimus as a last option. ${ }^{78}$ The choice of everolimus for second-line treatment is supported by the results of a randomized, controlled, Phase III study, mainly investigated in third and later lines. ${ }^{79}$ This study proved that everolimus is as effective after two TKIs as it is after one.

The only head-to-head retrospective study available as a comparison of the two classes of drugs indicated that anti-VEGFs prolong time to treatment failure more than mTORs inhibitors. The two drugs do not appear to have a difference in OS. ${ }^{80}$

An original approach to solving the dilemma of the best second line of treatment was proposed by Porta et al. ${ }^{78}$ They affirm that it is well known that a large percentage of everyday clinical decisions do not take into account evidence-based medicine. With the goal of defining a clinical practice evaluation of the correct second line of therapy, the authors report that it is important to initially evaluate the effects induced by first-line TKI treatment on patient QoL and tumor burden. Every single situation should be managed differently, with the aim of individualizing the treatment for each patient as much as possible. Experience in our center suggests the integration of this algorithm with a careful assessment of the risks and benefits of treatment for each patient, evaluating dimension of the tumor, comorbidities, and lifestyle of the patients. Before a decision on the best second-line therapy is made, we suggest an assessment of the overall health status and profile of individual patients. It should be carried out with an exhaustive evaluation of the concomitant pathologies, such as chronic obstructive pulmonary disease, hypothyroidism, brain metastasis, and diabetes. Everolimus should be avoided in patients with preexistent toxicities such as chronic obstructive pulmonary disease and diabetes. An evaluation of patient lifestyle should also be performed. TKIs should be avoided in patients with activity where hands and feet are frequently involved. Moreover, our experience suggests that everolimus should not be used as a second line of therapy for symptomatic patients or those with large tumors where reduction is desirable. Those patients should be treated with a second-line TKI therapy.

Further sorafenib development in RCC is related to adjuvant/neoadjuvant therapy and TKI sequence studies. Given the activity of sorafenib in advanced disease, two Phase III trials are ongoing to evaluate sorafenib in earlystage disease. The goal is to minimize the risk of disease 
recurrence after surgery. There is also interest in the use of sorafenib in the neoadjuvant setting. In these studies, goals are the cytoreduction of big primary tumor bulk or the conversion of unresectable primary tumors into a surgically operable one. Moreover, in the near future, data from these studies could solve many questions regarding longer-term clinical outcomes of sorafenib, providing important information related to safety and feasibility on the long-term use of the drug.

Regardless of studies about the best sequence strategy, data available from retrospective studies indicate that the sequence of sorafenib followed by sunitinib is able to maximize the use of targeted therapies and to optimize patient outcomes. As previously reported, a Phase III trial (SWITCH) is ongoing, and results should solve this dilemma.

In conclusion, contemplating the history of RCC therapy, sorafenib appears to be a milestone. In fact, sorafenib is the first target therapy that has proven activity in a randomized, Phase III trial. Moreover, the use of sorafenib in clinical trials and in clinical practice has displayed, for the first time in $\mathrm{RCC}$, the importance of clinical benefit and stable disease, in addition to RR, driving the scientific community to new endpoints for clinical trial design.

\section{Disclosure}

The authors report no conflicts of interest in this work.

\section{References}

1. McLaughlin JK, Lipworth L. Epidemiologic aspects of renal cell cancer. Semin Oncol. 2000;27(2):115-123.

2. Vogelzang NJ, Stadler WM. Kidney cancer. Lancet. 1998;352(9141): 1691-1696.

3. Godley PA, Taylor M. Renal cell carcinoma. Curr Opin Oncol. 2001; 13(3):199-203.

4. Pantuck AJ, Zisman A, Belldegrun AS. The changing natural history of renal cell carcinoma. J Urol. 2001;166(5):1611-1623.

5. Campbell SC, Flanigan RC, Clark JI. Nephrectomy in metastatic renal cell carcinoma. Curr Treat Options Oncol. 2003;4(5):363-372.

6. Storkel S, Eble JN, Adlakha K, et al. Classification of renal cell carcinoma: Workgroup No. 1. Union Internationale Contre le Cancer (UICC) and the American Joint Committee on Cancer (AJCC). Cancer. 1997; 80(5):987-989.

7. Amato RJ. Chemotherapy for renal cell carcinoma. Semin Oncol. 2000; 27(2):177-186.

8. Rey PM, Villavicencio H. Sorafenib: tolerance in patients on chronic hemodialysis: a single-center experience. Oncology. 2008;74(3-4): 245-246.

9. Coppin C, Porzsolt F, Awa A, et al. Immunotherapy for advanced renal cell cancer. Cochrane Database Syst Rev. 2005;1:CD001425.

10. Yang JC, Rosenberg SA. An ongoing prospective randomized comparison of interleukin-2 regimens for the treatment of metastatic renal cell cancer. Cancer J Sci Am. 1997;3 Suppl 1:S79-S84.

11. Gitlitz BJ, Belldegrun A, Figlin RA. Immunotherapy and gene therapy. Semin Urol Oncol. 1996;14(4):237-243.

12. Davies H, Bignell GR, Cox C, et al. Mutations of the BRAF gene in human cancer. Nature. 2002;417(6892):949-954.
13. Alavi A, Hood JD, Frausto R, et al. Role of Raf in vascular protection from distinct apoptotic stimuli. Science. 2003;301(5629): 94-96.

14. Hood JD, Bednarski M, Frausto R, et al. Tumor regression by targeted gene delivery to the neovasculature. Science. 2002;296(5577): 2404-2407.

15. Thomas GV, Tran C, Mellinghoff IK, et al. Hypoxia-inducible factor determines sensitivity to inhibitors of mTOR in kidney cancer. Nat Med. 2006;12(1):122-127.

16. Kim WY, Kaelin WG. Role of VHL gene mutation in human cancer. $J$ Clin Oncol. 2004;22(24):4991-5004.

17. Escudier B, Eisen T, Stadler WM, et al. Sorafenib in advanced clear-cell renal-cell carcinoma. N Engl J Med. 2007;356(2): 125-134.

18. Motzer RJ, Hutson TE, Tomczak P, et al. Sunitinib versus interferon alfa in metastatic renal-cell carcinoma. $N$ Engl $J$ Med. 2007;356(2):115-124.

19. Sternberg CN, Davis ID, Mardiak J, et al. Pazopanib in locally advanced or metastatic renal cell carcinoma: results of a randomized Phase III trial. J Clin Oncol. 2010;28(6):1061-1068.

20. Hudes G, Carducci M, Tomczak P, et al. Temsirolimus, interferon alfa, or both for advanced renal-cell carcinoma. $N$ Engl $J$ Med. 2007;356(22):2271-2781.

21. Motzer RJ, Escudier B, Oudard S, et al. Efficacy of everolimus in advanced renal cell carcinoma: a double-blind, randomised, placebocontrolled Phase III trial. Lancet. 2008;372(9637):449-456.

22. Escudier B, Bellmunt J, Negrier S, et al. Phase III trial of bevacizumab plus interferon alfa-2a in patients with metastatic renal cell carcinoma (AVOREN): final analysis of overall survival. $J$ Clin Oncol. 2010;28(13):2144-2150.

23. Rini BI, Halabi S, Rosenberg JE, et al. Phase III trial of bevacizumab plus interferon alfa versus interferon alfa monotherapy in patients with metastatic renal cell carcinoma: final results of CALGB 90206. J Clin Oncol. 2010;28(13):2137-2143.

24. Wilhelm S, Carter C, Lynch M, et al. Discovery and development of sorafenib: a multikinase inhibitor for treating cancer. Nat Rev Drug Discov. 2006;5(10):835-844.

25. Chang YS, Adnane J, Trail PA, et al. Sorafenib (BAY 43-9006) inhibits tumor growth and vascularization and induces tumor apoptosis and hypoxia in RCC xenograft models. Cancer Chemother Pharmacol. 2007;59(5):561-574.

26. Veronese ML, Mosenkis A, Flaherty KT, et al. Mechanisms of hypertension associated with BAY 43-9006. J Clin Oncol. 2006;24(9): $1363-1369$.

27. Keating GM, Santoro A. Sorafenib: a review of its use in advanced hepatocellular carcinoma. Drugs. 2009;69(2):223-240.

28. Lathia C, Lettieri J, Cihon F, et al. Lack of effect of ketoconazolemediated CYP3A inhibition on sorafenib clinical pharmacokinetics. Cancer Chemother Pharmacol. 2006;57(5):685-692.

29. Furuse J, Ishii H, Nakachi K, et al. Phase I study of sorafenib in Japanese patients with hepatocellular carcinoma. Cancer Sci. 2008;99(1): 159-165.

30. Abou-Alfa GK, Schwartz L, Ricci S, et al. Phase II study of sorafenib in patients with advanced hepatocellular carcinoma. J Clin Oncol. 2006;24(26):4293-4300.

31. Porta C, Bracarda S. Presente e futuro di sorafenib in oncologia - Ed Accademia Nazionale di Medicina. Genoa: Forum Service; 2011.

32. Clark JW, Eder JP, Ryan D, et al. Safety and pharmacokinetics of the dual action Raf kinase and vascular endothelial growth factor receptor inhibitor, BAY 43-9006, in patients with advanced, refractory solid tumors. Clin Cancer Res. 2005;11(15):5472-5480.

33. Strumberg D, Schultheis B, Adamietz IA, et al. Phase I dose escalation study of telatinib (BAY 57-9352) in patients with advanced solid tumors. Br J Cancer. 2008;99(10):1579-1585.

34. Miller AA, Murry DJ, Owzar K, et al. Phase I and pharmacokinetic study of sorafenib in patients with hepatic or renal dysfunction: CALGB 60301. J Clin Oncol. 2009;27(11):1800-1805. 
35. Strumberg D, Voliotis D, Moeller JG, et al. Results of Phase I pharmacokinetic and pharmacodynamic studies of the Raf kinase inhibitor BAY 43-9006 in patients with solid tumors. Int J Clin Pharmacol Ther. 2002;40(12):580-581.

36. Awada A, Hendlisz A, Gil T, et al. Phase I safety and pharmacokinetics of BAY 43-9006 administered for 21 days on/7 days off in patients with advanced, refractory solid tumors. Br J Cancer. 2005;92(10): 1855-1861.

37. Ratain MJ, Eisen T, Stadler WM, et al. Phase II placebo-controlled randomized discontinuation trial of sorafenib in patients with metastatic renal cell carcinoma. J Clin Oncol. 2006;24(16):2505-2512.

38. Maroto-Rey P, Bellmunt J, Trigo JM et al. First-line phase II trial of sorafenib (BAY 43-9006) in patients with advanced renal cell carcinoma unsuitable for cytokine treatment. ASCO Annual Meeting Proceedings. J Clin Oncol, 2007; I(25)Supp18:15640.

39. Szczylik C, Demkow T, Staehler M, et al. Randomised phase II trial of firstline treatment with sorafenib versus interferon in patients with advanced renal cell carcinoma: final results. J Clin Oncol 2007;25(18):5025.

40. Escudier B, Eisen T, Stadler WM, et al. Sorafenib for treatment of renal cell carcinoma: final efficacy and safety results of the Phase III treatment approaches in renal cancer global evaluation trial. J Clin Oncol. 2009;27(20):3312-3318

41. Hahn OM, Yang C, Medved M, et al. Dynamic contrast-enhanced magnetic resonance imaging pharmacodynamic biomarker study of sorafenib in metastatic renal carcinoma. J Clin Oncol. 2008;26(28): 4572-4578.

42. Lamuraglia M, Escudier B, Chami L, et al. To predict progression-free survival and overall survival in metastatic renal cancer treated with sorafenib: pilot study using dynamic contrast-enhanced Doppler ultrasound. Eur J Cancer. 2006;42(15):2472-2479.

43. Stadler WM, Figlin RA, McDermott DF, et al. Safety and efficacy results of the advanced renal cell carcinoma sorafenib expanded access program in North America. Cancer. 2010;116(5):1272-1280.

44. J Beck, G Procopio, U Keilholz, et al. Final results of the European Advanced Renal Cell Carcinoma Sorafenib (EU-ARCCS) expandedaccess study: a large open-label study in diverse community settings. Ann Oncol. February 15, 2011. [Epub ahead of print].

45. Nexavar FDA product information. http://berlex.bayerhealthcare.com/ html/products/pi/Nexavar_PI.pdf. Accessed March 1, 2011.

46. Hutson TE, Bellmunt J, Porta C, et al. Long-term safety of sorafenib in advanced renal cell carcinoma: follow-up of patients from Phase III TARGET. Eur J Cancer. 2010;46(13):2432-2440.

47. Tolcher AW, Appleman LJ, Shapiro GI, et al. A Phase I open-label study evaluating the cardiovascular safety of sorafenib in patients with advanced cancer. Cancer Chemother Pharmacol. June 3, 2010. [Epub ahead of print].

48. Parsa VK, Heilbrun L, Smith D, et al. Safety and efficacy of sorafenib therapy in patients with metastatic kidney cancer with impaired renal function [abstract 365]. Proceedings of the 2008 Genitourinary Cancers Symposium.

49. Rathmell WK, Chen S. VHL inactivation in renal cell carcinoma: implications for diagnosis, prognosis and treatment. Expert Rev Anticancer Ther. 2008;8(1):63-73.

50. Choueiri TK, Plantade A, Elson P, et al. Efficacy of sunitinib and sorafenib in metastatic papillary and chromophobe renal cell carcinoma. J Clin Oncol. 2008;26(1):127-131.

51. Golshayan AR, George S, Heng DY, et al. Metastatic sarcomatoid renal cell carcinoma treated with vascular endothelial growth factor-targeted therapy. J Clin Oncol. 2009;27(2):235-241.

52. Bellmunt J, Eisen T, Szczylik C, et al. A new patient-focused approach to the treatment of metastatic renal cell carcinoma: establishing customized treatment options. BJU Int. 2010 [Epub ahead of print].

53. Aapro MS, Kohne CH, Cohen HJ, Extermann M. Never too old? Age should not be a barrier to enrollment in cancer clinical trials. Oncologist 2005;10(3):198-204.

54. Extermann M, Hurria A. Comprehensive geriatric assessment for older patients with cancer. J Clin Oncol. 2007;25(14):1824-1831.
55. Eisen T, Oudard S, Szczylik C, et al. Sorafenib for older patients with renal cell carcinoma: subset analysis from a randomized trial. J Natl Cancer Inst. 2008;100(20):1454-1463.

56. Bukowski RM. Renal cell carcinoma: a model system for novel drug development? Clin Genitourin Cancer. 2008;6(1):7-8.

57. Porta C, Paglino C, Imarisio I, Ferraris E. Sorafenib tosylate in advanced kidney cancer: past, present and future. Anticancer Drugs. 2009;20(6):409-415.

58. Bukowski R, Cella D, Gondek K, Escudier B. Effects of sorafenib on symptoms and quality of life: results from a large randomized placebo-controlled study in renal cancer. Am J Clin Oncol. 2007;30(3): 220-227.

59. Beck J, Procopio G, Negrier S, et al. Final analysis of a large open-label, noncomparative study of sorafenib in European patients with advanced RCC (EU-ARCCS) [poster]. Presented at the 34th ESMO Annual Congress; September 20-24, 2009. Berlin, Germany.

60. Flaherty KT, Brose MS. Sorafenib-related hand-foot skin reaction improves, not worsens, with continued treatment. Clin Cancer Res. 2009;15(24):7749.

61. Lacouture $\mathrm{ME}, \mathrm{Wu} \mathrm{S}$, Robert $\mathrm{C}$, et al. Evolving strategies for the management of hand-foot skin reaction associated with the multitargeted kinase inhibitors sorafenib and sunitinib. Oncologist. 2008; 13(9):1001-1011

62. Lacouture ME, Reilly LM, Gerami P, Guitart J. Hand foot skin reaction in cancer patients treated with the multikinase inhibitors sorafenib and sunitinib. Ann Oncol. 2008;19(11):1955-1961.

63. Nexavar EMA product information: http://www.ema.europa.eu/ docs/en_GB/document_library/EPAR_-_Product_Information/ human/000690/WC500027704.pdf. Accessed March 1, 2011.

64. Orphanos GS, Ioannidis GN, Ardavanis AG. Cardiotoxicity induced by tyrosine kinase inhibitors. Acta Oncol. 2009;48(7):964-970.

65. Halbert RJ, Figlin RA, Atkins MB, et al. Treatment of patients with metastatic renal cell cancer: a RAND Appropriateness Panel. Cancer. 2006;107(10):2375-2383.

66. National Comprehensive Cancer Network. NCCN guidelines for renal cell carcinoma. V 2.2011 http://www.nccn.org/professionals/physician_gls/f_guidelines.asp. Accessed March 1, 2011.

67. Bellmunt J, Fishman M, Eisen T, Quinn D. Expert opinion on the use of first-line sorafenib in selected metastatic renal cell carcinoma patients. Expert Rev Anticancer Ther. 2010;10(6):825-835.

68. Escudier B, Szczylik C, Hutson TE, et al. Randomized Phase II trial of first-line treatment with sorafenib versus interferon a-2a in patients with metastatic renal cell carcinoma. J Clin Oncol. 2001;27(8):1280-1289.

69. Ryan CW, Goldman BH, Lara PN Jr, et al. Sorafenib with interferon alfa-2b as first-line treatment of advanced renal carcinoma: a Phase II study of the Southwest Oncology Group. J Clin Oncol. 2007;25(22): 3296-3301.

70. Jonasch E, Corn P, Pagliaro LC, et al. Upfront, randomized, Phase 2 trial of sorafenib versus sorafenib and low-dose interferon alfa in patients with advanced renal cell carcinoma: clinical and biomarker analysis. Cancer. 2010;116(1):57-65.

71. Garcia JA, Hutson TE, Elson P, et al. Sorafenib in patients with metastatic renal cell carcinoma refractory to either sunitinib or bevacizumab. Cancer. 2010;116(23):5383-5390.

72. Kontovinis L, Laschos K, Karadimou A, et al. Sequential treatment with sorafenib and sunitinib in metastatic renal cell carcinoma: clinical outcomes from a retrospective clinical study. Med Oncol. January 30, 2011. [Epub ahead of print].

73. Tamaskar I, Garcia JA, Elson P, et al. Antitumor effects of sunitinib or sorafenib in patients with metastatic renal cell carcinoma who received prior antiangiogenic therapy. J Urol. 2008;179(1):81-86; discussion 86.

74. Beck J, Procopio G, Bajetta E, et al. Final results of the European Advanced Renal Cell Carcinoma Sorafenib (EU-ARCCS) expandedaccess study: a large open-label study in diverse community settings. Ann Oncol. February 15, 2011. [Epub ahead of print].

75. Sablin MP, Negrier S, Ravaud A, et al. Sequential sorafenib and sunitinib for renal cell carcinoma. J Urol. 2009;182(1):29-34; discussion 34 
76. Dudek AZ, Zolnierek J, Dham A, et al. Sequential therapy with sorafenib and sunitinib in renal cell carcinoma. Cancer. 2009;115(1):61-67.

77. De Reijke TM, Bellmunt J, van Poppel H, et al. EORTC-GU group expert opinion on metastatic renal cell cancer. Eur J Cancer. 2009;45(5): 765-773.

78. Porta C, Paglino C, Imarisio I. Sequencing tyrosine kinase inhibitors or immediately switching to mTOR inhibitors in advanced kidney cancer: a critical review. European J Clin Med Oncol. December 21, 2010. [Epub ahead of print].
79. Motzer RJ, Escudier B, Oudard S, et al. Phase 3 trial of everolimus for metastatic renal cell carcinoma: final results and analysis of prognostic factors. Cancer. 2010;116(18):4256-4265.

80. Vickers MM, Choueiri TK, Rogers M, et al. Clinical outcome in metastatic renal cell carcinoma patients after failure of initial vascular endothelial growth factor-targeted therapy. Urology. 2010;76(2): $430-434$.

\section{Publish your work in this journal}

The Open Access Journal of Urology is an international, peer-reviewed, open access journal publishing original research, reports, editorials, reviews and commentaries on all aspects of adult and pediatric urology in the clinic and laboratory including the following topics: Pathology, pathophysiology of urological disease; Investigation and treatment of urological disease; Pharmacology of drugs used for the treatment of urological disease. The manuscript management system is completely online and includes a very quick and fair peer-review system, which is all easy to use. Visit http://www.dovepress.com/testimonials.php to read real quotes from published authors.

Submit your manuscript here: http://www.dovepress.com/open-access-journal-of-urology-journal 